\title{
Regeneration of industrial cutting blades made from $\times 39$ Cr13 steel used in skinning process of pleuronectidae-family flatfishes
}

Bartosz ZIELIŃSKI, Wojciech KAPŁONEK, Krzysztof NADOLNY

DOI: 10.30464/jmee.2018.2.4. 277

Cite this article as:

Zieliński B., Kapłonek W., Nadolny K. Regeneration of industrial cutting blades made from X39Cr13 steel used in skinning process of pleuronectidae-family flatfishes. Journal of Mechanical and Energy Engineering, Vol. 2(42), No. 4, 2018, pp. 277-284.

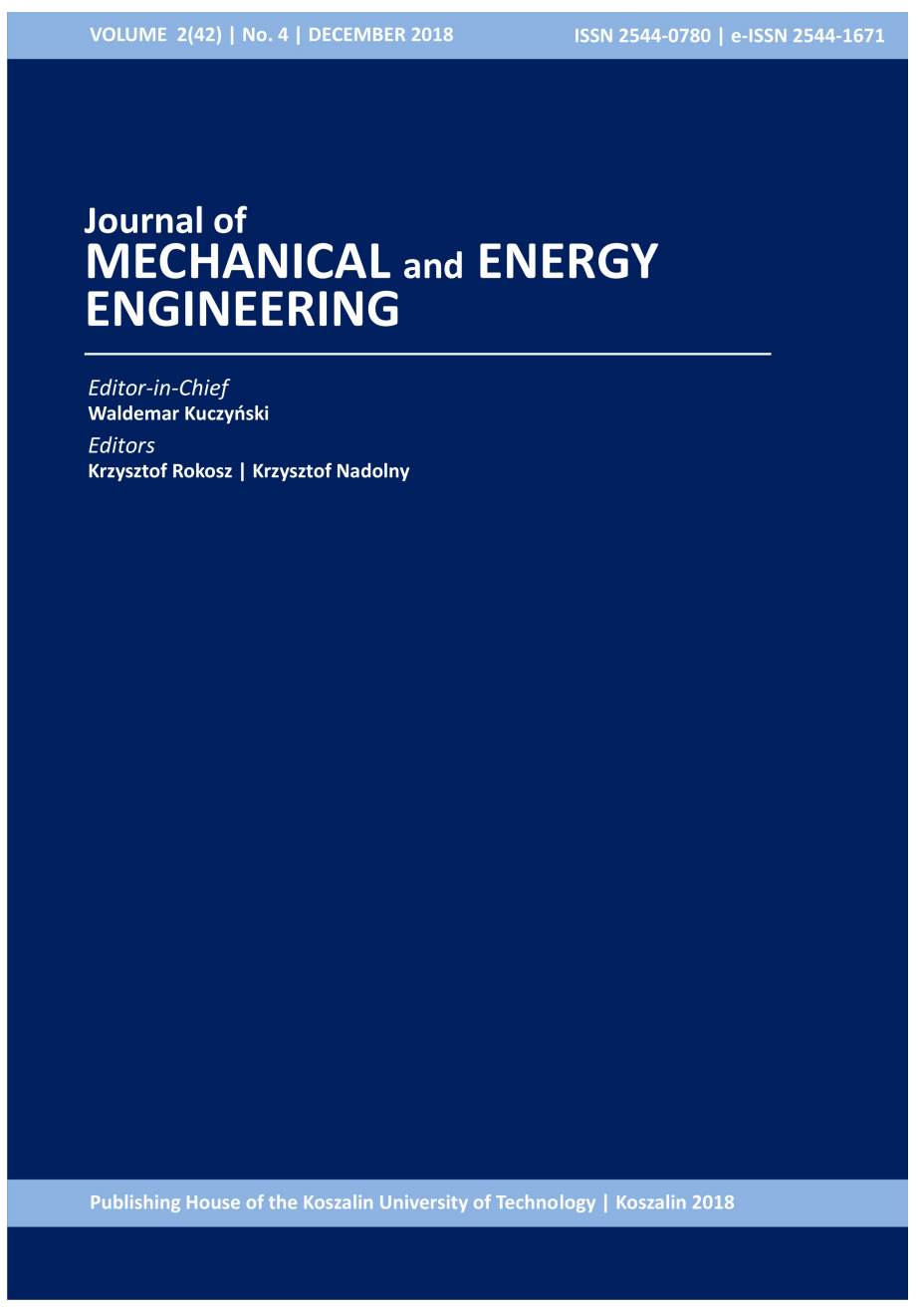

Journal of Mechanical and Energy Engineering

Website: jmee.tu.koszalin.pl

ISSN (Print): 2544-0780

ISSN (Online): 2544-1671

Volume: 2(42)

Number: 4

Year: 2018

Pages: 277-284

Article Info:

Received 22 November 2018

Accepted 14 December 2018

\section{Open Access}

This article is distributed under the terms of the Creative Commons Attribution 4.0 (CC BY 4.0) International License (http://creativecommons.org/licenses/by/4.0/), which permits unrestricted use, distribution, and reproduction in any medium, provided you give appropriate credit to the original author(s) and the source, provide a link to the Creative Commons license, and indicate if changes were made. 


\title{
REGENERATION OF INDUSTRIAL CUTTING BLADES MADE FROM X39Cr13 STEEL USED IN SKINNING PROCESS OF PLEURONECTIDAE-FAMILY FLATFISHES
}

\author{
Bartosz ZIELIŃSKI $^{{ }^{*}}$, Wojciech KAPŁONEK ${ }^{2}$, Krzysztof NADOLNY ${ }^{3}$ \\ 1* Espersen Koszalin Sp. o.o., Mieszka I 29, 75-124 Koszalin, Poland, e-mail: b.zielinski@espersen.com \\ ${ }^{2}$ Department of Production Engineering, Faculty of Mechanical Engineering, Koszalin University of \\ Technology, Racławicka 15-17, 75-620 Koszalin, Poland, e-mail: wojciech.kaplonek@tu.koszalin.pl, \\ ${ }^{3}$ Department of Production Engineering, Faculty of Mechanical Engineering, Koszalin University of \\ Technology, Racławicka 15-17, 75-620 Koszalin, Poland, e-mail: krzysztof.nadolny@tu.koszalin.pl
}

(Received 22 November 2018, Accepted 14 December 2018)

\begin{abstract}
One of the important and still current problems occurring in the fish processing industry is the intensive wear of the cutting surface of industrial cutting blades used to separate the fish raw material. In the paper, the proposes a proprietary solution to the above problem consisting in the regeneration of worn surfaces realized in the process of precise grinding by the use of a prototype 5-axis CNC grinding machine was presented. The obtained machining results were verified, among others on the basis of measurements of values of the cutting edges inclination angles and analysis of values of selected surface roughness parameters. The proposed solution along with the developed methodology can be an interesting alternative to typical ways of renewing the cutting ability of cutting tools in applications from the fish processing industry.
\end{abstract}

Keywords: Industrial cutting blade, wear of the cutting edge, regeneration process, CNC grinding machine, precision grinding, surface roughness analysis

\section{INTRODUCTION}

Specificity of the manufacturing operations carried out in the modern food industry, especially in its fields related to the processing of fish, described in detail in the work of Sen, Boziaris and Borda et al. [1-3], requires the use of many (sometimes complex) processing operations leading to effective separation of fish raw material. One of such operations is the processing of the raw material in order to remove unwanted elements (including fins, heads, bones, spine) and to give it the right shape and dimensions. Part of the processing is skinning, described in the works of Hall $[4,5]$, consisting in separating the fillet (flap of meat, bone, bone and skin free) from the fish. In this case, the technological machines operating in an automatic or manual cycle, are usual used. They are equipped with a single industrial cutting blades or their units containing in some cases even 6-8 knives or more, with may be stationary in relation to the feedstock being fed, or they may perform reciprocating motion. In Fig. 1 as an example of the above mentioned machines, the fish skinning machines produced by Cretel nv (Eeklo, Belgium) are presented.

Industrial cutting blades are mainly made of carbon and alloy tool steels, high speed steels as well as stainless steels, characterized in the work of Colás and Totten [6]. The latter are most often used in the food industry and are allowed for contact with food. Because the skinning process is one of the key operations determining the target weight of the semifinished product and its shape and dimensions, as indicated in the work of Hall [4], processors place great emphasis on maintaining a short process time and its high efficiency. This process may be derange by the occurrence of a number of unfavorable factors, hindering or (in some cases) preventing its further conduct. They are most often related to the surface condition of the cutting tool. On this condition have a significant impact, i.a.: 

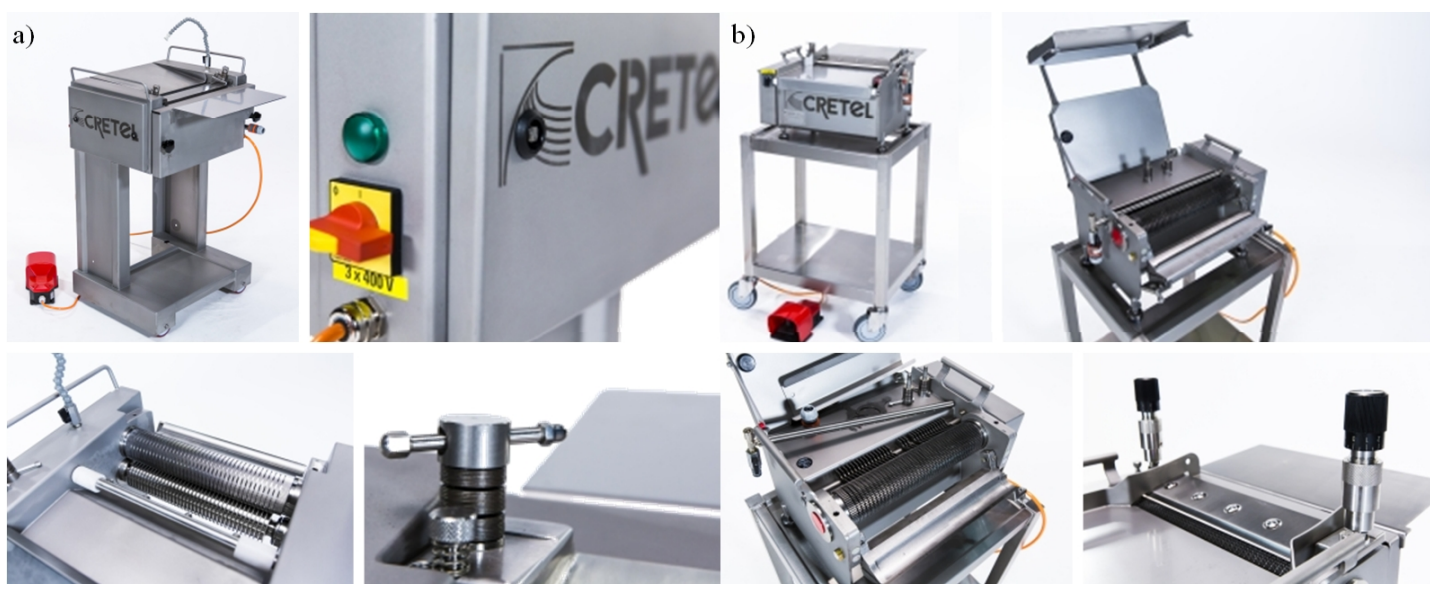

Fig. 1. General view and details of fish skinning machines produced by Cretel nv (Eeklo, Belgium): a) series $365-$ compact free-standing skinning units with manual infeed; b) series 362 - compact bench top machines [7]

- factors conducive to the formation of strong corrosive interactions (including moist working environment, use of alkaline compounds and phosphates for decontamination and protection of the raw material against microorganisms, use of nitric and phosphoric acid for removing postproduction sediments),

- factors conducive to mechanical wear, mainly the change of cutting edge geometry of the industrial cutting blades as a result of the machining process (e.g. including the dulling of cutting edges,

- factors favoring the change of material properties, leading to increase its susceptibility to deformation.

Regardless of whether one of the above-mentioned factors or their combination occurs, seeks to minimize the effects of their occurrence mainly due to economic reasons. Downtime of technological machines operating in the production line related to the exchange of cutting blades is usually long-lasting and costly, moreover, the cost of a new good-quality blades is also high. For minimalization of the last of above, in industrial practice often the activities related to the renewing the cutting ability of the machining tools by their regeneration are applied. In the case of industrial cutting blades, is aim to obtain their original shape and, above all, to reproduce the correct values of inclination angles of the cutting edges. Effective regeneration can be carried out by the use of e.g., grinding process with abrasive tools made of grains with cubic boron nitride $(\mathrm{cBN})$ and bonded by ceramic binder, characterized in the work of Jackson and Davim [8].

In the further part of this paper, the authorial proposal for the regeneration of cutting surfaces of industrial cutting blades by the use of a prototype 5axis CNC grinding machine will be presented and discussed. Geometrical analysis of cutting edges inclination angles as well as surface roughness, needed when verifying the correctness of carried out machining process, will be additionally discussed.

\section{SURFACE CHARACTERISTICS OF INDUSTRIAL CUTTING BLADES IN THE BEFORE AND AFTER MACHINING CONDITION}

In the experimental studies, a low stiffness industrial cutting blades (Steen FPM International, Kalmthout, Belgium) in the before and after machining condition, were used by the authors. The second of the mentioned tools were intensively used during skinning process of Pleuronectidae-family flatfishes - mainly the Baltic species of flounder (Platichthys flesus trachurus) and plaice (Platessa platessa baltica), whose detailed description was given in the work of Gibson et al. [9].

For the experiments a set of six industrial blades (reference, $\mathrm{R}-2$ pieces, after-machining condition, B2-B5 - (total) 4 pieces) were prepared.

All of the tools were made of X39CR13 steel. This chromium martensitic stainless steel is used in kitchen utensils (high quality kitchen knives, cutlery), pharmaceutical industry, biomedical engineering (surgical blades), mechanical engineering (rolling bearings, springs, parts exposed to abrasion) and precision engineering (elements of measurement instruments). The chemical composition and selected properties of material is given in Tab. 1 and Tab. 2, respectively, whereas the general view of the industrial cutting blades in before and after machining condition are presented in Fig. 2. In Fig. 2b, the geometrical shape of surface of industrial cutting blade on which three areas are distinguished, each having a different chamfering angle can be clearly analyzed. During the skinning process, Area 1 (A1) is the most exploited. This area is a key part of the blade and has direct contact with fish material. The cutting edge in this area is the most vulnerable to mechanical damage. It's an area of strong intensification of wear phenomena. Direct contact with the raw material has also Area 2 (A2), but is not as exposed to adverse phenomena as 
Tab. 1. Chemical composition of X39CR13 chromium martensitic stainless steel

\begin{tabular}{cccccccc}
\hline Element $^{1)}$ & $\mathrm{Fe}$ & $\mathrm{C}$ & $\mathrm{Si}$ & $\mathrm{Mn}$ & $\mathrm{P}$ & $\mathrm{S}$ & $\mathrm{Cr}$ \\
\hline Concentration, $\%$ & $83.00-87.10$ & $0.36-0.42$ & 1.00 & 1.00 & 0.04 & 0.015 & $12.5-14.5$ \\
\hline Deviation & \pm 0.02 & \pm 0.02 & +0.05 & +0.03 & +0.005 & +0.003 & \pm 0.15 \\
\hline${ }^{1)}$ According with EN & $10088-1: 2014$ & & & & &
\end{tabular}

Tab. 2. Selected properties of X39CR13 chromium martensitic stainless steel

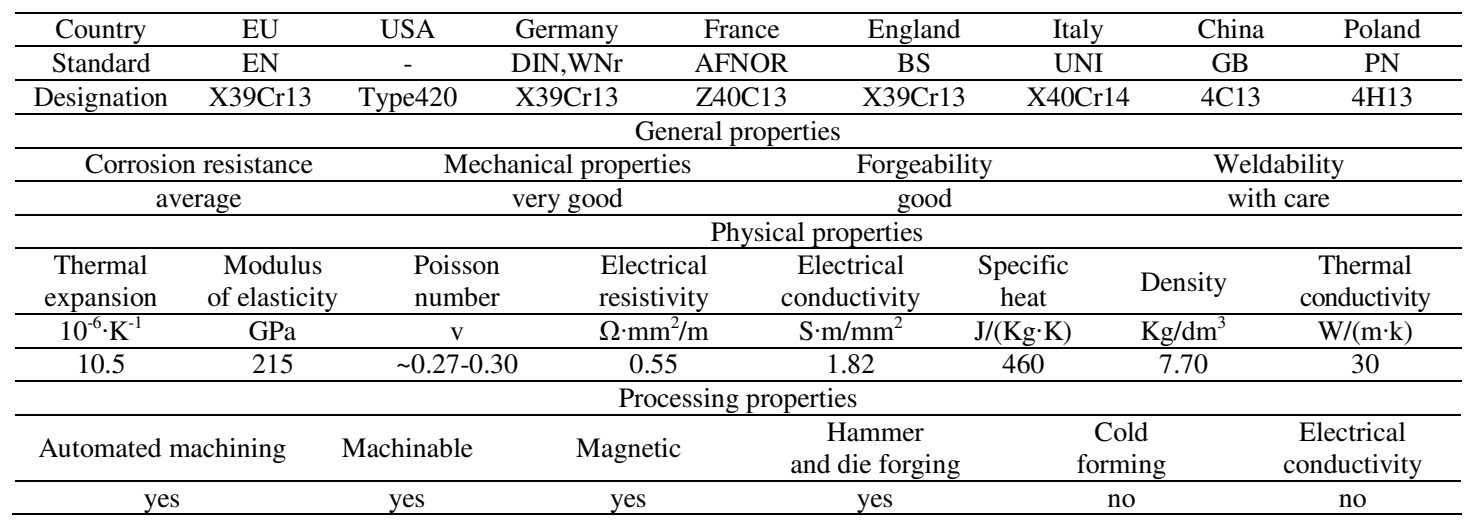
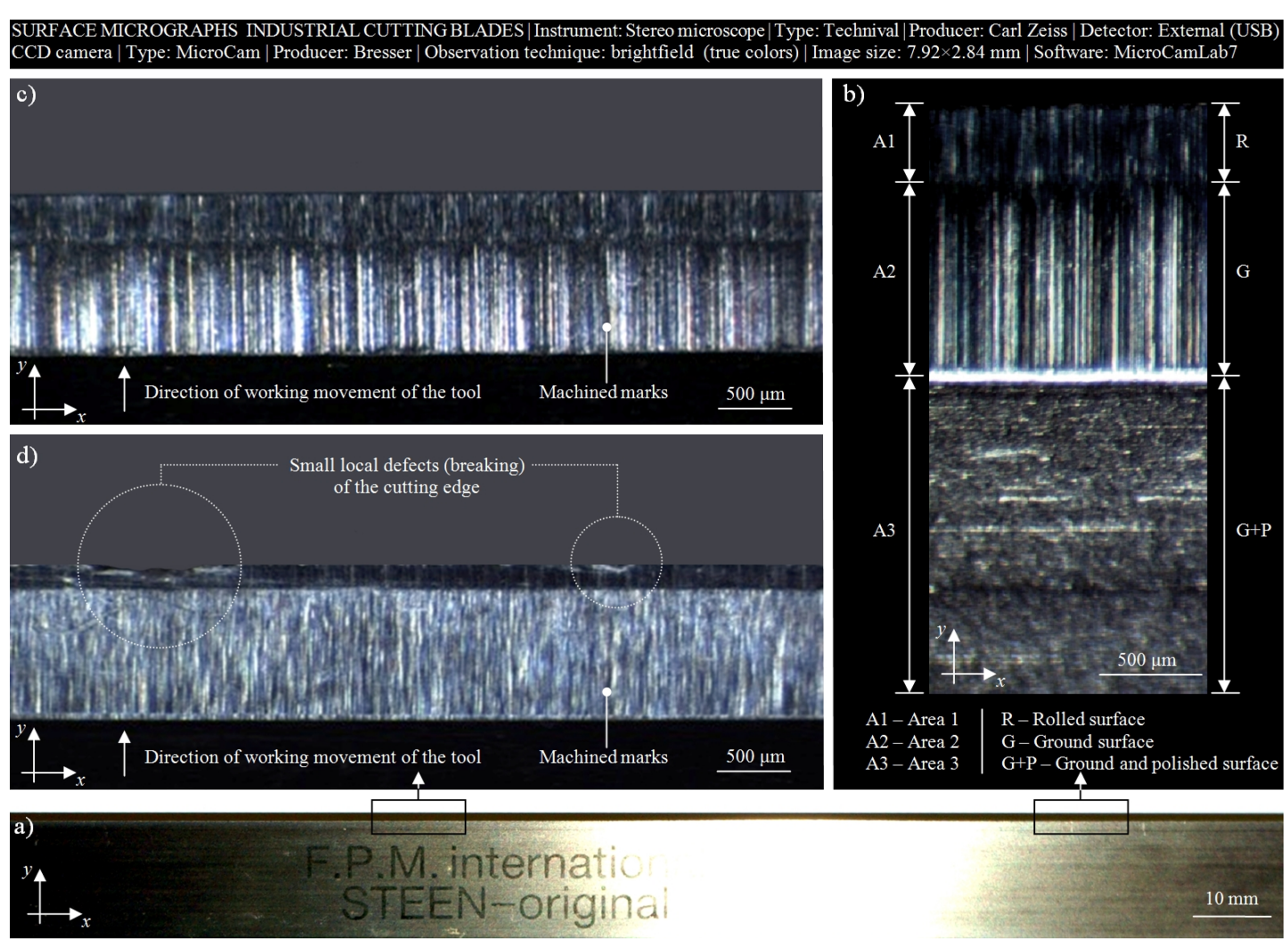

Fig. 2. Surfaces of industrial cutting blades for X39CR13 steel used in experimental studies obtained by brightfield technique by the use of stereo microscope Technival (Carl Zeiss, Jena, Germany) equipped with CCD camera MicroCam 10MP (Bresser, Rhede, Germany): a) general view of industrial cutting blade in before machining condition (dimensions: $459.50 \times 12.30 \times 0.60 \mathrm{~mm}$, hardness: $>61.00 \mathrm{HRC}$ ); b) micrograph of a fragment of industrial cutting blade in before machining condition with marked three areas corresponding to three machining; c) micrograph of a fragment of blade in before machining condition; d) micrograph of a fragment of industrial cutting blade in after machining condition (with visible surface defects) 


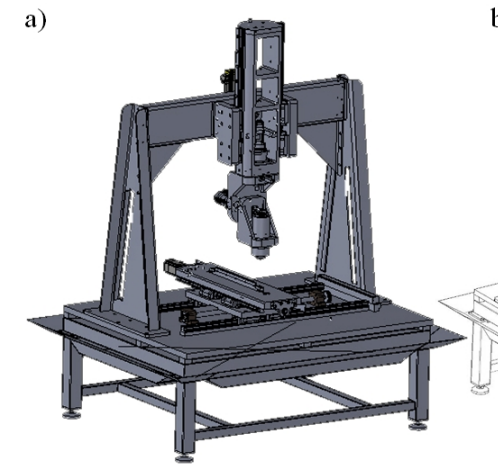

b)
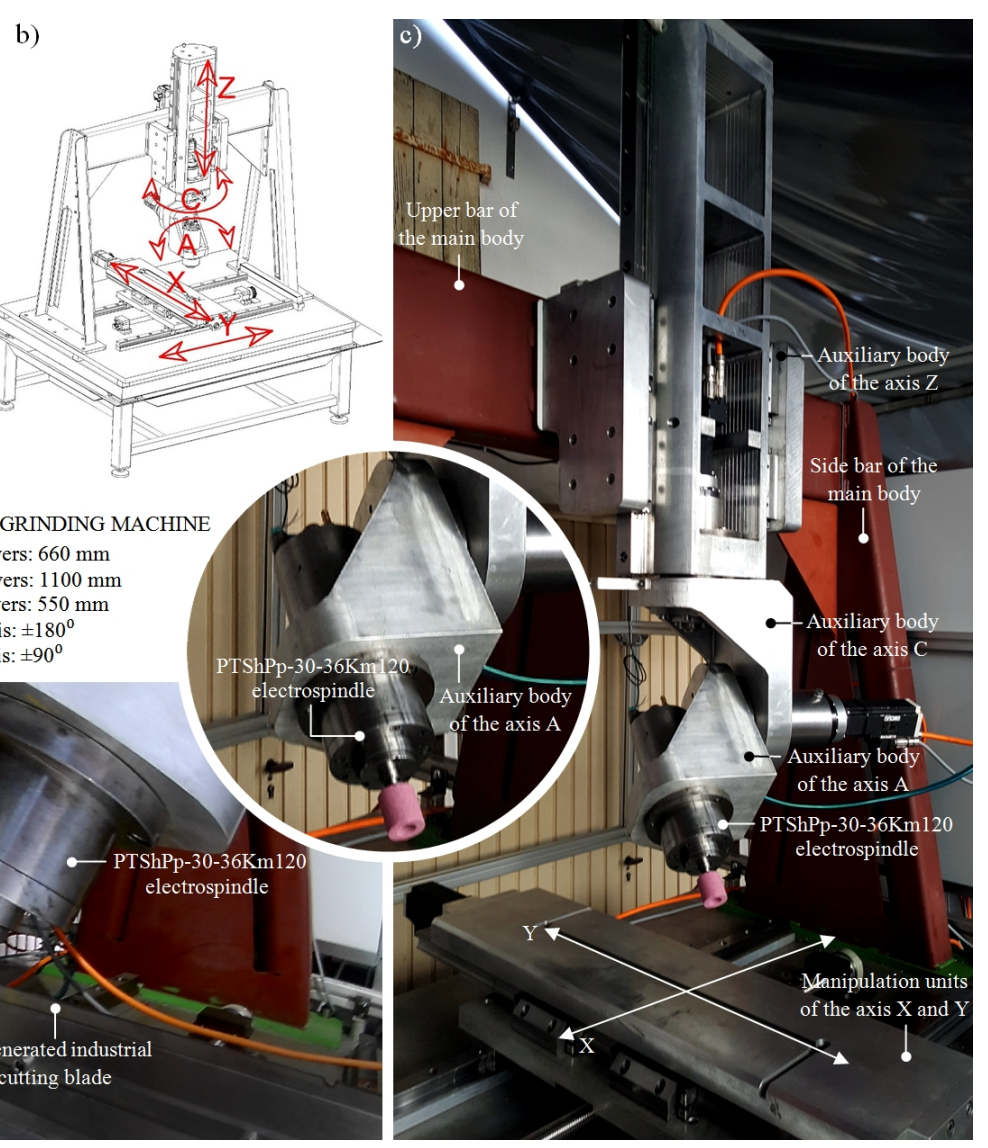

BASIC SPECIFICATION OF THE 5-AXIS CNC GRINDING MACHINE

Total weight: $1200 \mathrm{~kg} \quad$ Range of $X$ axis travers: $660 \mathrm{~mm}$ Height: $2400-2850 \mathrm{~mm} \quad$ Range of Y axis travers: $1100 \mathrm{~mm}$ Length: $2300 \mathrm{~mm} \quad$ Range of $Z$ axis travers: $550 \mathrm{~mm}$ \begin{tabular}{l|l} 
Width: $2360 \mathrm{~mm}$ & Rotation in the $\mathrm{C}$ axis: $\pm 180^{\circ}$ \\
Rotation in the $\mathrm{A}$ axis: $\pm 90^{\circ}$
\end{tabular}
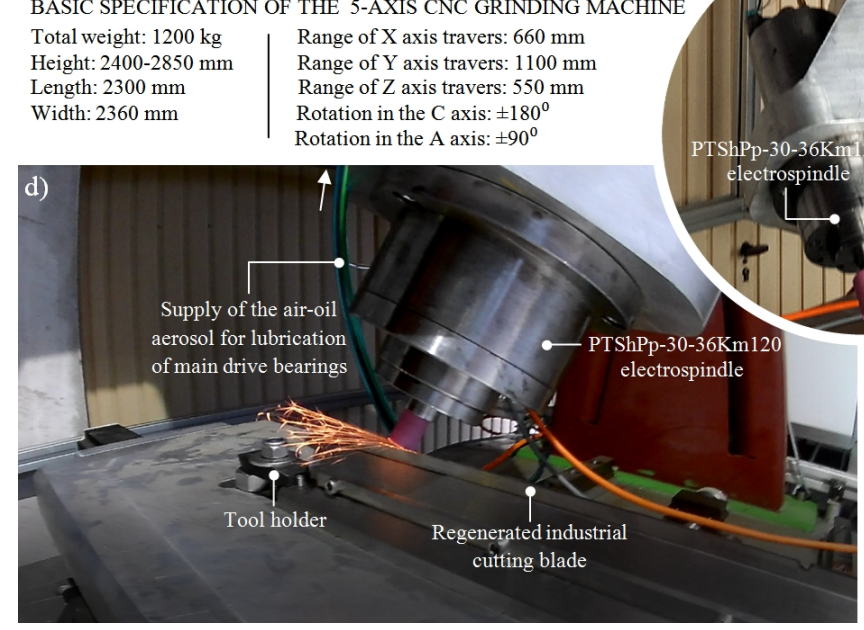

Fig. 3. Prototype 5-axis CNC grinding machine for shaping of the industrial cutting tools used in experimental studies: a) computer model of the machine during design process; b) kinetic scheme of the machine with marked directions of axis $\mathrm{X}, \mathrm{Y}$ and $\mathrm{Z}$ motions as well as axis $\mathrm{A}$ and $\mathrm{C}$ rotation; c) general view of the prototype with main body, guides of the axis $\mathrm{X}$ and $\mathrm{Y}$ and electrospindle; $\mathrm{d}$ ) machine during regeneration (grinding process) of industrial cutting blade

Area 1 (A1). In Area 2 (A2), a numerous machining marks perpendicular to the cutting edge, characteristic of the grinding process, are visible. Indirect contact with the raw material has also Area 3 (A3). It is an area that is not involved in the process, it fulfills the role of the plane fixing the tool in the technological machine.

The main factor deciding about the withdrawal of the used industrial cutting blade from operation is the strong deformation of its cutting edge (loss of straightness), causing excessive dimensional and shape errors of the processed fish semi-finished product. In the described case, the intensive exploitation of the industrial cutting blades in production conditions revealed the edge deformation on which a number of typical forms of wear make impossible the further conduct of the process. In Fig. 2d, a small local defects of material that could lead to final damage to the fish stock as a result of further work and deepening the breaking process are presented. Small losses of material (such as those shown in Fig. 2d), due to their small depth (slight material losses) give a chance for full regeneration of the cutting edge of such a tool.

Similar (Fig. 2d) and other forms of wear appearing on the cutting tools in wide areas of applications were shown and discussed also in the work of Nordström and Bergström [10], Darmawan et al. [11], Zhou et al. [12], Ghosh at al., [13], Chayeuski et al. [14], Jang et al. [15] as well as in websites [16-18].

\section{REGENERATION PROCESS OF INDUSTRIAL CUTTING BLADES}

Modern regeneration processes are becoming more and more popular methods of restoring the original features of the machining tool surfaces. The key issue in the case of industrial cutting blades used in the food industry is to reproduce the correct values of inclination angles of the cutting edges. Useful in this respect is the analysis of machining marks of the blades in before machining process condition, allowing to determine approximately the kinematics of abrasive machining and analysis of forms of wear enabling the determination of the values of the grinding process parameters.

After conducting the above analyzes, a regeneration process was started, in which a specially designed and constructed a prototype 5-axis CNC grinding machine was used. The general view of above machine and its main components is presented in Fig. 3. 
The technological machine was made of a lower body, made of cold-formed profiles in the shape of a truss of $120 \times 120 \times 6 \mathrm{~mm}$, on which a structure consisting of two side bars and upper bar twisted together into a single main body forming the upper body. In its central part, a structure composed with an auxiliary bodies of the axis $\mathrm{Z}$ (travel in the range 0 $550 \mathrm{~mm}$ ), $\mathrm{C}$ and $\mathrm{A}$ (rotations in the range $\pm 180^{\circ}$ and $\pm 90^{\circ}$, respectively), was fasten. At their end a direct main drive was placed in the form of a PTShPp-3036Km120 electrospindle (FŁT Kraśnik SA, Kraśnik, Poland), allowing to obtain the speed range $n=30,000$ $36,000 \mathrm{rpm}$ at the power $P=2.7-3.2 \mathrm{~kW}$.

In the spindle of 5-axis CNC grinding machine, a grinding wheel with technical designation T6-16× 20x $6-4 \times 8-98$ A60L9VC40 was placed. By the rotate of the abrasive tool was performed a main working movement of abrasive tool, while the spindle of technological machine was making the infeed movement. Before regeneration process the industrial cutting blade was precisely oriented and fixed on a table performing movements along the $\mathrm{X}$ and $\mathrm{Y}$ axis (in the range $0-660 \mathrm{~mm}$ and 0 $1100 \mathrm{~mm}$, respectively). Next the grinding process started with the following parameters: grinding wheel rotational speed $n_{s}=30,000-36,000 \mathrm{rpm}$, radial table feed speed while grinding $v_{f r}=450 \mathrm{~min}^{-1}$. The process was carried out without the use of a cooling lubricant.

\section{VERIFICATION OF CORRECTNESS OF THE REGENERATION PROCESS}

The correctness of carried out machining process was verified on the basis of the analysis of the values of the cutting edge angles of the remanufactured industrial cutting blades and the values of selected surface roughness parameters in these areas. Data for both analyzes were obtained as a result of contact measurements realized with the use of advanced stylus profilometer Hommel-Tester T8000 (Hommelwerke GmbH, Villingen-Schwenningen, Germany) (Fig. 4) and processing in HommelMap Basic 3.1 software using Mountains Technology ${ }^{\mathrm{TM}}$ (Digital Surf, Besançon, France).

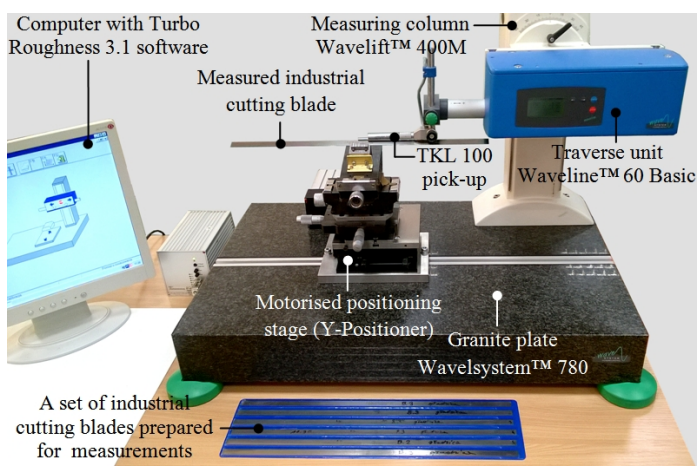

Fig. 4. Stylus profilometer Hommel-Tester T8000 used during experimental studies for measurements of selected features of industrial cutting blades a)

b)

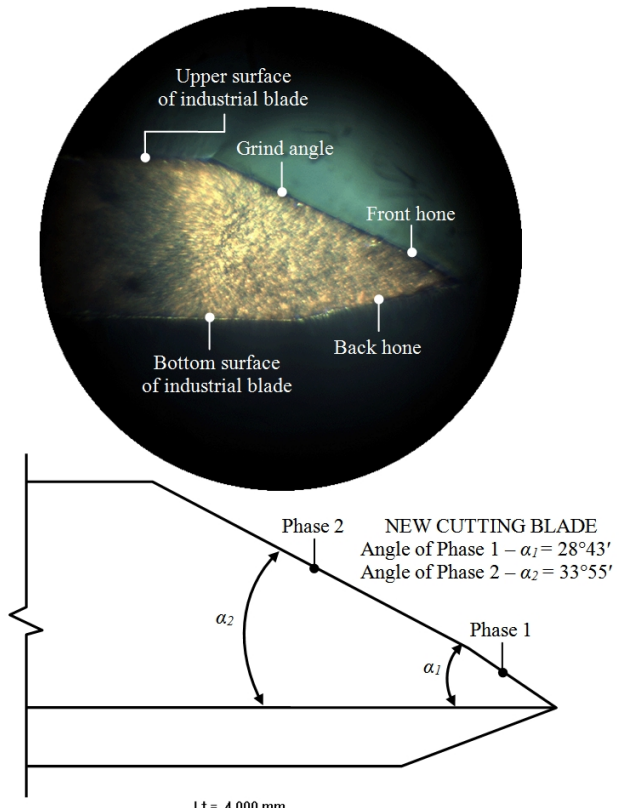

c)
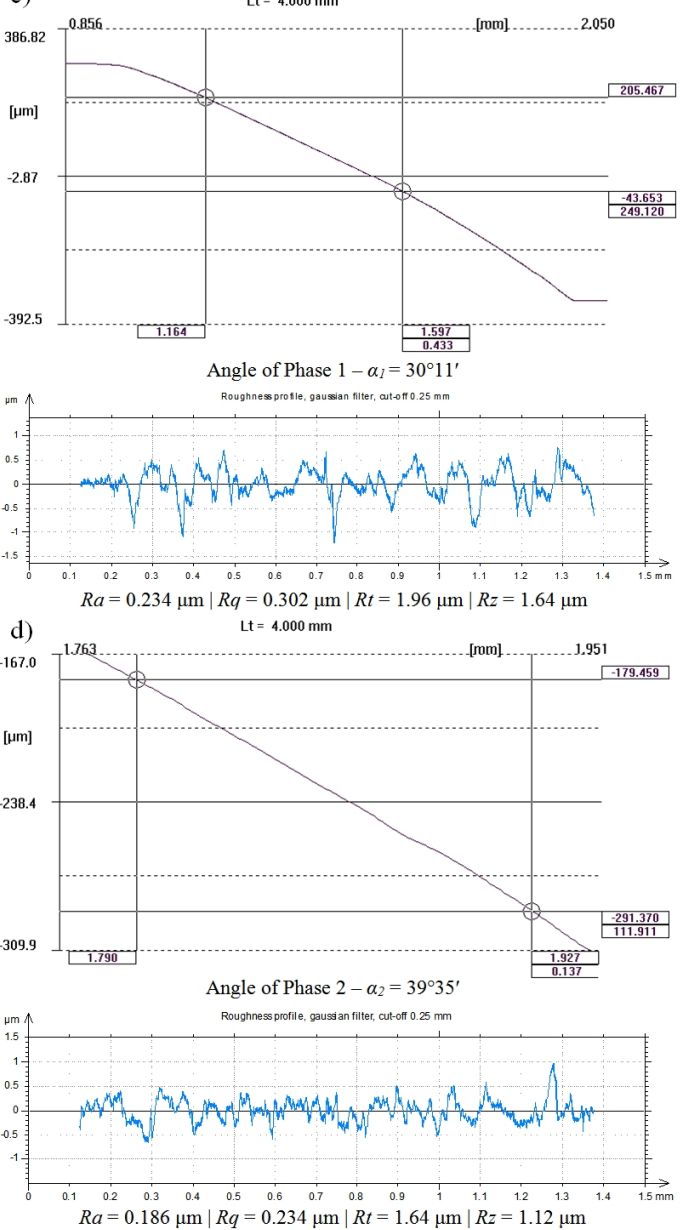

Fig. 5. Geometry of industrial cutting blade as well as measurements of the angles and surface profile for Phase 1 and 2: a) micrograph of the cutting edge of the blade; b) schematic diagram of measured angles; value of the angle and selected roughness (profile) parameters obtained for sample's B2: c) Phase 1; b) Phase 2 

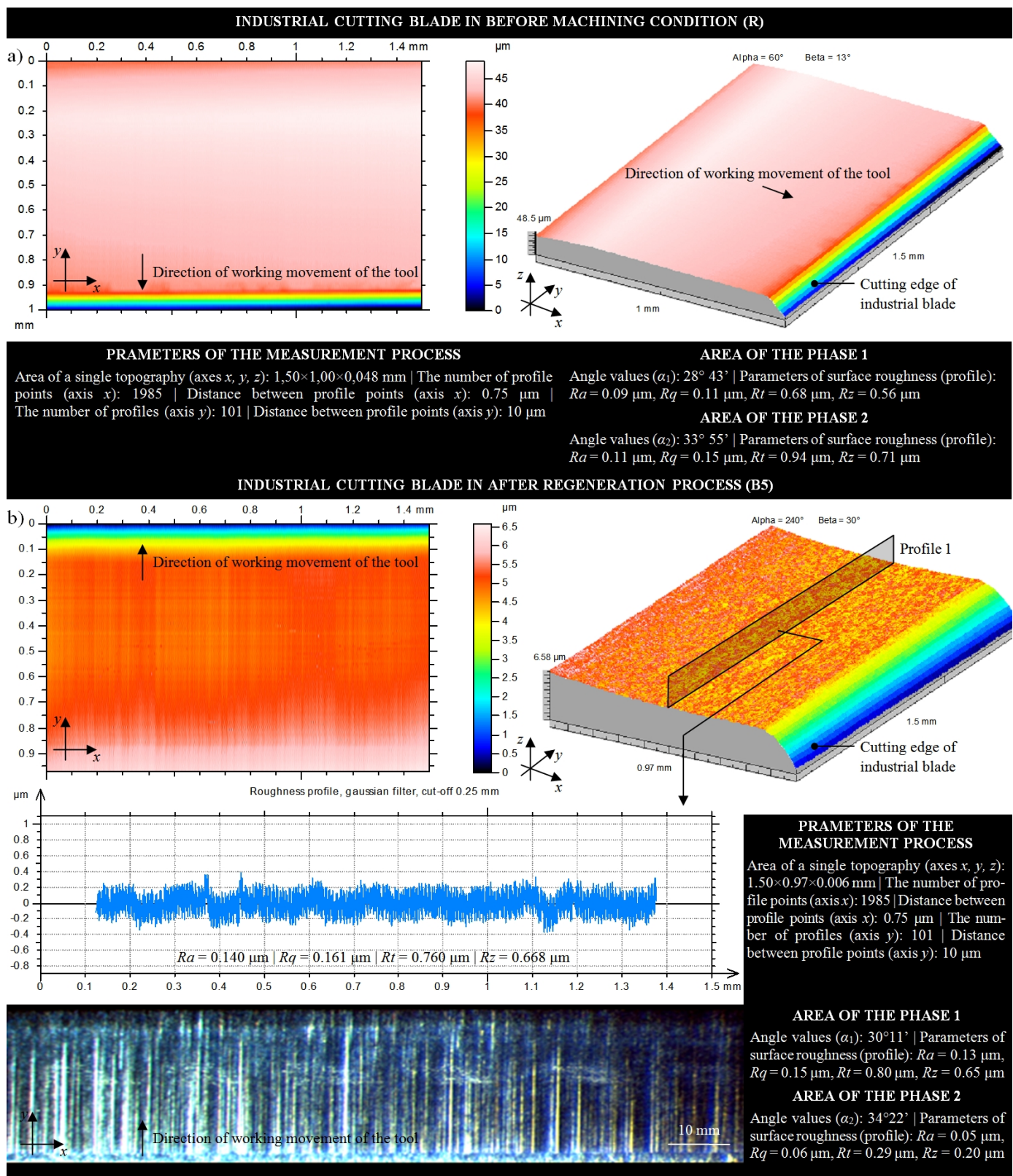

Fig. 6. Collection of example results of analyzes carried out in the HommelMap Basic 3.1 software for: a) reference industrial cutting blade (R); b) industrial cutting blade (B5) after the regeneration process

In Fig. 5 the geometry of analysed industrial cutting blade is presented. From geometrically point of view the cutting edge was divided into two phases (Fig. 5b). As the area of the Phase 1, the area located at a distance of $0.03 \mathrm{~mm}$ from the cutting edge was assumed, while for the area of the Phase 2 the area located at a distance of $0.05 \mathrm{~mm}$ from the cutting edge of the analyzed industrial cutting blade was assumed. For the reference blade $(\mathrm{R})$ in the after machining condition, the nominal angle in the area of the Phase 1 was $28^{\circ} 43^{\prime}$, while for the in the area of the Phase 2 was $33^{\circ} 55^{\prime}$. For the industrial cutting blades subjected to the regeneration process the angles values in the area of the Phase 1 were in the range from $30^{\circ} 11^{\prime}$ to $30^{\circ} 50^{\prime}$, whereas in the area of the Phase 2 , they were from $34^{\circ} 22^{\prime}$ to $41^{\circ} 30^{\prime}$, respectively. As results from the analysis of the above values, it wasn't possible to fully restore the value of the inclination of the cutting edges. Percent deviations from the nominal size were from $5.1 \%$ to $7.6 \%$ (area of the Phase 1) and from $1.33 \%$ to $21.03 \%$ (area of the Phase 2), respectively. They were, on the one hand, very close to the expected values, and on the other hand they showed long deviations from the assumed values. This situation requires intensification of works related to the modification of the settings (entry parameters) of the 
used technological machine tool and their testing. As an example of calculation of the values of inclination angle are results obtained for sample B2 (Phase 1 and 2). They were given in Fig. 5c-d. Additionally, for these phases the surface roughness profiles with selected parameters were shown.

Additionally, for selected areas of each industrial cutting blade, analysis of selected surface roughness (profile) parameters was carried out. The set of parameters included $R a, R q, R t$ and $R z$ according the ISO 428720 standard [19]. The nominal values for the reference industrial cutting blade $(\mathrm{R})$ were respectively: $R a=0.09 \mu \mathrm{m}, R q=0.11 \mu \mathrm{m}, R t=0.68 \mu \mathrm{m}$ and $R z=0.56 \mu \mathrm{m}$ (area of the Phase 1) as well as $R a=0.11$ $\mu \mathrm{m}, R q=0.15 \mu \mathrm{m}, R t=0.94 \mu \mathrm{m}$ and $R z=0.71 \mu \mathrm{m}$ (area of the Phase 2). For the industrial cutting blades (B2-B5) after the regeneration process the values of parameters were in the range of: $R a=0.08-0.23 \mu \mathrm{m}$, $R q=0.11-0.30 \mu \mathrm{m}, R t=0.75-1.96 \mu \mathrm{m}$ and $R z=0.64-$ $1.64 \mu \mathrm{m}$ (area of the Phase 1) as well as $R a=0.05$ $0.18 \mu \mathrm{m}, R q=0.06-0.23 \mu \mathrm{m}, R t=0.29-1.64 \mu \mathrm{m}$, and $R z=0.25-1.12 \mu \mathrm{m}$ (area of the Phase 2). The obtained values were generally equal to or higher than the nominal values, which was also observed when analyzing the inclination angles of the cutting edges. This indicates the difficulty of restoring the fully assumed values of both the inclination angles of the cutting edges as well as the nominal values of the surface roughness para-meters in the two considered areas of regenerated indu- strial cutting blades. Exemplary comparison of reference industrial cutting blade (R) and one of the blades (B5) after the regeneration process is shown in Fig. 6. The set of analyses contains a $2 \mathrm{D}$ contour map with the height coded in the indexed colors, the surface topo-graphy with extracted a single profile, calculated sur-face roughness (profile) parameters and micrograph of the surface after the regeneration process.

\section{CONCLUSIONS}

The subjects concerning renewing the cutting ability of machining tools, with particular emphasis on tools used for material separation, are present in the areas of mechanical engineering for several decades. A great advance in the area of precision machining with the use of CNC technological machines has introduced a new quality in the field. This results in the increasing use of various types of competitive regenerative processes, which are (in many criteria) competitive in relation to traditional production and utilization.

In this work, the proposal of regeneration process of industrial cutting blades realized in the process of precise grinding by the use of a prototype 5 -axis $\mathrm{CNC}$ grinding machine was presented. The obtained results of the process can be considered relatively good, although the carried out experiments revealed a number of difficulties in fully restoring the original properties of the industrial cutting blades. They concern both achieving the assumed precision of the shaping of the blade angles as well as the desired surface roughness of the machined surface. Differences, in the case of angles shaping, were higher by $7 \%$ (Phase 1) and by $21 \%$ (Phase 2), than values obtained for reference blade. The obtained values of surface roughness (profile) were higher by $39 \%(R a), 29 \%(R q), 34 \%(R t)$ and $34 \%(R z)$ (Phase 1) as well as by $61 \%(R a), 65 \%$ $(R q), 57 \%(R t)$ and $>63 \%(R z)$ (Phase 2).

In further work, the authors plan a constructional modification of the $\mathrm{CNC}$ grinding machine used and an improvement of the experimental methodology of machining, which will allow to obtain much more beneficial effects and complete implementation of the regeneration process of industrial cutting tools.

\section{Nomenclature}

$$
\begin{aligned}
& \text { Symbols } \\
& \alpha_{1} \quad-\text { angle of Phase } 1 \text {, }^{\circ} \\
& \alpha_{2} \quad-\text { angle of Phase 2, } \\
& n_{s} \quad \text { - grinding wheel rotational speed, } \min ^{-1} \\
& v_{f r} \quad-\text { radial table feed speed while grinding, } \mathrm{mm} \cdot \mathrm{min}^{-1} \\
& \mathrm{Ra} \quad \text { - arithmetical mean deviation of the roughness } \\
& \text { profile, } \mu \mathrm{m} \\
& R q \quad \text { - root mean square deviation of the roughness } \\
& \text { profile, } \mu \mathrm{m} \\
& R t \quad-\text { total height of the roughness profile, } \mu \mathrm{m} \\
& R z \quad-\text { maximum height of the profile within a sampling } \\
& \text { length, } \mu \mathrm{m}
\end{aligned}
$$

\section{Acronyms}

cBN - Cubic Boron Nitride

CCD - Charge-Coupled Device

CNC - Computerized Numerical Control

HRC - Rockwell C Hardness

\section{References}

1. Sen D.P. (2005). Advances in fish processing technology. Allied Publishers, New Dehli.

2. Boziaris I. S. (Ed.). (2013). Seafood processing: Technology, quality and safety. John Wiley \& Sons, Chichester.

3. Borda D., Nicolau A.I., Raspor P. (2017). Trends in fish processing technologies. CRC Press, Boca Raton.

4. Hall G.M. (Ed.) (2011). Fish processing: sustainability and new opportunities. John Wiley \& Sons, New York.

5. Hall G.M. (2012). Fish processing technology (2nd Edition). Springer Science \& Business Media, London.

6. Colás R., Totten G.E. (2016). Encyclopedia of iron, steel, and their alloys. CRC Press, New York.

7. Cretel nv (2018). Fish skinning [Online available: 15.11.2018], https://www.cretel.be/en/fish-skinning

8. Jackson M.J., Davim J.P. (Eds.) (2010). Machining with abrasives. Springer Science+Business Media, New York.

9. Gibson R.N., Nash R.D., Geffen, A.J., Van der Veer H.W. (Eds.) (2014). Flatfishes: biology and exploitation (Fish and aquatic resources series 16). John Wiley \& Sons, Chichester.

10. Nordström J., Bergström J. (2001). Wear testing of saw teeth in timber cutting. Wear, Vol. 250, No. 1-12, pp. 19-27. 
11. Darmawan W., Quesada, J. Rossi F., Marchal R., Machi F., Usuki H. (2009). Improvement in wear characteristics of the AISI M2 by laser cladding and melting. Journal of Laser Applications, Vol. 21, No. 4, pp. 176-182.

12. Zhou H., Qiu S., Huo Y., Zhang N. (2013). High-speed dicing of silicon wafers conducted using ultrathin blades. International Journal of Advanced Manufacturing Technology, Vol. 66, No. 5-8, pp. 947-953

13. Ghosh S.C., Heidari M., Hernández R.E., Blais C. (2015). Patterns of knife edge recession in an industrial chippercanter. Forest Products Journal, Vol. 65, No.7, pp. 358364.

14. Chayeuski V.V., Grishkevich A.A., Zhylinski V.V. (2015). Modification wood milling tool by alloy coatings Ni-CO, Ni-P and combined ZrN-Ni-Co coatings. Technical Service of Agriculture Forestry and Stransport Systems, Vol. 3, pp. 163-167.

15. Jang J.S.C., Tsai P.H., Shiao A.Z., Li T.H., Chen C.Y., Duh J.G., Chen M.J., Chang S.H., Huang W.C (2015). Enhanced cutting durability of surgical blade by coating with Fe-based metallic glass thin film. Intermetallics, Vol. 65 , pp. $56-60$

16. Hertzmann P. (2018). À la carte [Online available: 15.11 2018], https://www.hertzmann.com/articles/2013/edges/

17. Scienceofsharp (2018). [Online available: 15.11.2018], https://scienceofsharp.wordpress.com/

18. Larrin T. (2018). Knife steel nerds - Metallurgy and testing of knives and steel [Online available: 15.11.2018], https://knifesteelnerds.com/2018/08/06/sharpness-vscutting-ability/

19. ISO 4287 (1997). Geometrical Product Specifications (GPS) - Surface Texture: Profile Method: Terms, Definitions and Surface Texture Parameters. International Organization for Standardization, Geneva.

\section{Biographical note}

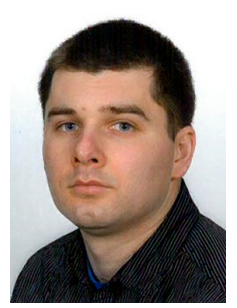

Bartosz Zieliński received his M.Sc. degree in Mechanics and Machine Design (specialization: Computer Techniques in Production Engineering) from Koszalin University of Technology (Koszalin, Poland) in 2005. In the same year, he started working for TEPRO S.A in Koszalin as the constructor of packaging machines. In 2007 stared working for Royal Greenland Seafood Sp. z o.o. in Koszalin as project leader where in 2014 change position on Technical manager. Currently, he is the technical manager in Espersen Koszalin Sp. o.o. His interests are focused on construction of machines (especially CNC-type) and production processes. Regardless of his professional work he is also a $\mathrm{PhD}$ student at the Faculty of Mechanical Engineering, Koszalin University of Technology, where currently preparing the doctoral thesis.

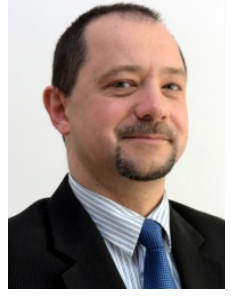

Wojciech Kapłonek (ORCID 00000003-4531-8963) received his MSc degree in Mechanics and Machine Design (specialization: Computer Applications in Engineering), $\mathrm{PhD}$ (with honors) and DSc in Machinery Construction and Operation (specialisation: Technical Metrology) from Koszalin University of Technology (Koszalin, Poland) in 2003, 2010 and 2018, respectively. Since 2007 he has been a researcher in the Department of Production Engineering at the Koszalin University of Technology, where currently he works as an associate professor in metrology and quality research team. He specializes in problems covering 2D/3D measurements and analyses of the machined surfaces obtained after the high-efficiency technological processes as well as selected issues related with image processing and analysis. He has participated in 2 international and 3 national research projects, as well as presenting results from his work at 8 international and 30 national conferences. He has authored and co-authored of 2 monographs and more than 120 scientific papers published in peer-review international and national journals, book chapters and conference proceedings. He is a member of Committee of Surface Engineering of the Polish Academy of Sciences.

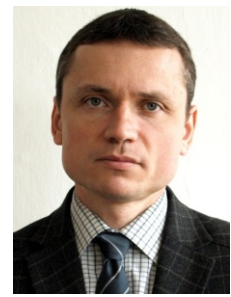

Krzysztof Nadolny (ORCID 00000002-2753-2782) received his M.Sc. degree in Mechanics and Machine Design and next Ph.D (with honors) as well as D.Sc. degree in Machinery Construction and Operation from Koszalin University of Technology (Koszalin, Poland), in 2001, 2006 and 2013, respectively. Since 2006 he has been a researcher in the Department of Production Engineering at the Koszalin University of Technology, where currently he works as an associated professor and head of research-didactic team for production planning and control. His scientific interests focus on problems concerning machining processes and tools, efficiency, monitoring and diagnostics of machining processes as well as tribology. He has participated in 2 international and 3 national research projects, presenting results of his work at 10 international and 21 national conferences, published more than 200 scientific papers in international and national journals, book chapters, as well as conference proceedings. He is also the author of 4 monographs and 9 national patents. 